\title{
Los límites del pensar: Hegel en diálogo con Kant
}

\author{
The Limits of Thinking: Hegel in Dialogue with Kant
}

\author{
Victor E. Duplancic \\ Universidad Nacional de Cuyo / Universidad de Congreso \\ duplancicv@ucongreso.edu.ar
}

\begin{abstract}
Resumen
Desde el horizonte de la duda cartesiana por la validez de la experiencia sensible para el conocimiento filosófico científico, se exploran los conceptos de límite del pensar a través del uso de las palabras kantianas de borde (Grenze) y barrera (Schranke) en su Crítica de la razón pura. A partir de allí se presenta el diálogo crítico de Hegel con Kant respecto a la limitación que éste último habría impuesto a la razón para el conocimiento verdadero de objetos filosóficos/metafísicos. Para ello se expone la posición hegeliana desde su tratamiento en el segundo capítulo (punto B. La finitud) de la primera sección de la Doctrina del ser (1832) y se hacen referencias a elementos conceptuales de la Fenomenología del espíritu.
\end{abstract}

Palabras claves: borde, barrera, finitud, frontera, dialéctica, experiencia.

\begin{abstract}
From the perspective of Cartesian doubt (on the validity of sensory experience in the acquisition of scientific philosophical knowledge), this article explores the concept of the limitations of reasoning through the use of the Kantian words 'boundary' (Grenze) and 'barrier' (Schranke) in his Critique of Pure Reason. Hegel's critical dialogue with Kant is presented focusing on the limitation that the latter imposed on reason for the acquisition of the true knowledge of philosophical/metaphysical objects. For this purpose, the Hegelian position is presented from its discussion on the second chapter (point B. Finitude) of the first section of the The Doctrine of Being (1832) and references are made to conceptual elements of the Phenomenology of Spirit.
\end{abstract}

Keywords: boundary, barrier, finitude, frontier, dialectics, experience.

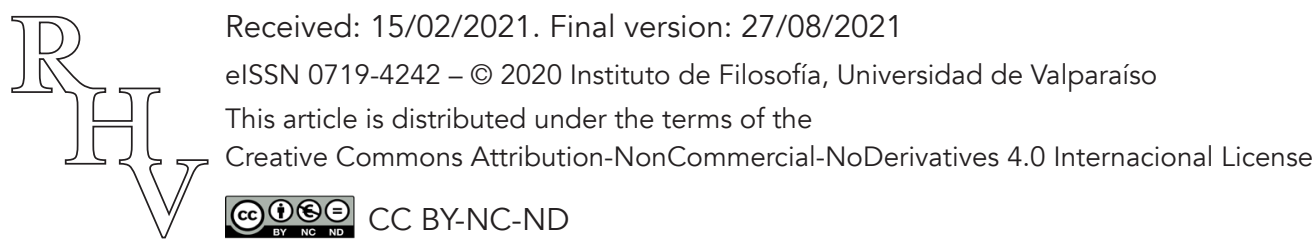




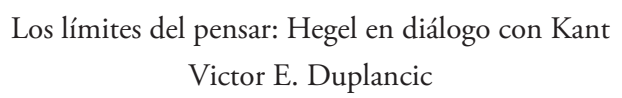

Se cuida mucho el mantenerse dentro de las barreras del pensar, de la razón, etc. y se afirma que no se puede ir más allá de esas barreras.

(Hegel 1985, 121)

\section{Introducción}

La ocasión de estos años nos invita a honrar a nuestro autor a 250 años de su nacimiento y 200 de sus Lineamientos fundamentales de la filosofía del derecho de un modo netamente filosófico: leyéndolo en el contexto que lo hizo filósofo: en el esfuerzo pensante de su vida por responder a las preguntas que él entendió la filosofía le ofrecía para ser aceptadas y respondidas. Nuestro aporte en este sentido es tomar uno de los variados temas de su filosofar, pero uno fundante: el de la posibilidad del sentido científico de la filosofía o, dicho en el lenguaje de la época, el de los límites de la razón para conocer, filosóficamente y de un modo científico, la realidad. Para ello hemos elegido recorrer brevemente los desafíos filosóficos que se le presentan a Descartes para luego ver la misma problemática enunciada por Kant y, de algún modo, respondida por Hegel. Para ello hacemos una reflexión sobre los términos que la filosofía usa en aquella época para referirse a este tópico: borde, frontera, barrera, límite, finitud. Estos términos, de larga tradición filosófica, entendemos que indican, señalan, hacia la auto-referencialidad del pensar que en dicho ejercicio se constituye, se consolida y se determina en la razón y justificación de su existir.

Pensar el límite (para nombrar a todos ellos con una palabra), ha sido para el pensar filosófico, según nuestro modo de comprender, el ejercicio necesario para ser y constituirse como algo con sentido. Constituirse lo entendemos aquí en el sentido de que, al pensar el límite, el pensar se piensa a sí mismo y se determina en su ser. Determinarse en su ser significaría llegar a ser algo concreto y expresado: idea, palabra, lenguaje, ciencia. Constituirse como algo con sentido significaría así que este algo devenido en su forma ideal-lingüística, se manifestaría como siendo la realidad bajo la forma de su poiêsis, de su transformación creativa humana. Pensar se constituiría así, a sí mismo, a partir de su limitación y, en el rigor de ese acto, expresaría lingüísticamente la realidad: la pensada y la natural. Pensar el límite sería así el primer y primigenio paso de auto-constituirse como pensar. Pensar el límite es, comprendido de este modo, devenir ser desde sí mismo, auto-poiêsis original. Pensar el límite sería entonces darse a sí, en tanto pensar, el sentido único y esencial para ser ciencia y no opinión o palabrería banal. Pensar el límite se convertiría en el acto necesario de la razón (del Lógos en su formulación griega) para devenir ciencia en tanto saber verdadero de la realidad. 
Dicho así, pensar el límite sería algo esencial al pensar mismo, en tanto éste pretende ser un hacer que devenga palabra verdadera, conocimiento efectivo de la realidad, verdad científica o, simplemente, verdad a secas.

Pensar el límite sería, de este modo, previo a toda teoría y a toda praxis. Pensar el límite es así pensar del pensar como auto-fundación de ser y sentido. Pensar el límite sería fundamentar el ser, la nada y el ente. En la sección ¿Con qué debe ser hecho el comienzo de la ciencia? Hegel escribía: "El comienzo de la ciencia absoluta debe ser, él mismo, comienzo absoluto, no debe ser presupuesto. Por lo tanto él no debe ser mediado por nada, ni tener un fundamento; él debe ser mas bien él mismo el fundamento de toda la ciencia" (Hegel 1978, 33). ${ }^{1}$ De este modo llega a ser el acto primero de toda metafísica y de toda física. Con ello estaríamos frente a la tarea inicial para encontrar y poner los primeros principios y causas del ser y del movimiento.

De este modo la exposición se orientará a presentar el diálogo filosófico Hegel-Kant en torno a los límites del pensar en, por lo menos, dos dimensiones: a) en una primera dimensión, límite sería considerado el fundamento absoluto sobre el cual se debe construir el edificio de la filosofía (o del pensar), b) en una segunda, límite sería considerado como los bordes que no pueden ser superados por dicho pensar, para seguir siendo, justamente, pensar filosófico verdadero, esto es, ciencia.

\section{Borde y barrera en Kant desde el horizonte del problema cartesiano de la verdad}

Cuando nos proponemos iniciar una exposición que de cuenta de un tema transversal, histórica y sistemáticamente, -en este caso, si incorporamos el antecedente cartesiano-, transversal a tres filósofos diferentes, siempre surge, con razón, la pregunta sobre la posibilidad de que dicho diálogo sea razonablemente justificable desde el horizonte de comprensión lingüístico en donde dicho diálogo quiere ser visto. Dicho de otro modo, si tal horizonte lingüístico fuera la disciplina filosófica, la pregunta sería: ¿es legítimo confrontar a tres filósofos diferentes respecto a un mismo tema, como si estuvieran hablando bajo las misma condiciones y reglas científicas y hermenéuticas? ¿o sus sistemas o pensamientos son inconmensurables? ¿O reconstruir un diálogo entre ellos es anacrónico? La posibilidad filosófica de resolver estas cuestiones ya la planteó, entre otros, Heidegger, en su confrontación pensante - justamente con Hegel. Allí afirma que la contemporaneidad se reconstruiría o se construiría en tanto ambos dialogantes dialoguen sobre lo mismo: sobre la cosa del pensar, sobre aquello que sería lo más controvertido en tanto habría sido lo más desafiante para cada pensador. (Heidegger 2006, 53; 1988, 45) Por ello tomamos acá el diálogo efectivamente realizado entre ellos sobre la cosa del pensar que para los

\footnotetext{
${ }^{1}$ En todos los casos las traducciones son propias.
} 
mismos, en sus respectivos tiempos y mundos lingüísticos, supuso un desafío filosófico semejante: en este caso, los límites de la filosofía, expresados en la pregunta por los límites de la razón.

En el proyecto kantiano de una fundamentación científica de la metafísica aparecen dos términos con relevancia en relación al concepto de límite. Estos términos son: frontera (Grenze) y límite (Schranke). Yo he traducido a los mismos en esta ocasión como borde (Grenze) y barrera (Schranke). Dicha traducción se justificará a partir de la exposición de lo que sigue.

Como veremos, en Kant podemos encontrar esta terminología para referirse a lo esencial de su proyecto filosófico, en relación, sobre todo, pero no exclusivamente, con las bases sistemáticas de una metafísica científica o filosofía como ciencia transcendental. Dichas bases serían puestas por una Crítica de la razón pura. El tema fundamental al que se enfrenta Kant y que se manifiesta como hilo conductor de toda la obra es estudiar la posibilidad de que la metafísica sea ciencia [B 22, 869] (Kant 1990, 53; 755). Que la metafísica sea ciencia nuevamente -habría que agregar- pues desde su nacimiento la metafísica era la ciencia primera, la ciencia de las ciencias por decirlo de algún modo. Claro que la repercusión de los profundos cambios que se produjeron en el ámbito de la física y de la ciencia natural a partir del siglo XVI son el marco natural para comprender la puesta en duda de la cientificidad de la metafísica. Para este proyecto kantiano es necesario, ante todo, establecer las condiciones de posibilidad de la cientificidad (o no) de dicha metafísica. Que ello se podría conseguir mediante un estudio del pensar no es una idea sola de Kant, Descartes sería el pensador que establece definitivamente que para filosofar es necesario comenzar con un examen crítico de nuestras facultades cognitivas (Secada 2002, XVII). Y, con ello, lleva la reflexión sobre el concepto de límite a su versión moderna. Puesto que pensar el límite no sólo sería realizar, poner, crear o encontrar el fundamento (Descartes 1973, 16). Se podría decir que pensar el límite para Descartes sería también pensar que la filosofía está teniendo dificultades para hacer lo propio de ella, esto es, decir los primeros fundamentos y causas del ser y del movimiento, o como lo postula él con el lenguaje de las problemáticas netamente metafísicas: fundamentar racionalmente el fundamento, esto es, los temas de la metafísica: Dios y alma (Descartes 1973, 2-3).

Lo que constata Descartes es que la filosofía ha llegado a su límite por un lado y, por otro, no encuentra límite en tanto piso. Y ha llegado a su límite porque ha traspasado el límite de la verdad, que es el de la certeza y la claridad racional. Fundamentar la metafísica sería darle límites en tanto piso y en tanto estructura que, al definirla en sus contornos y bordes, le de consistencia, esto es, le garantice verdad. Para definir los bordes o contornos de esa filosofía verdadera ante todo habría que entender que, para la filosofía, el límite es siempre límite entre la verdad y la falsedad. Si la filosofía es la ciencia de la verdad su contorno, su borde, su frontera es el límite con la no-verdad. Los límites del entendimien- 
Los límites del pensar: Hegel en diálogo con Kant

Victor E. Duplancic

to se constituyen a partir de su finitud, más allá sólo impera la voluntad infinita de querer la verdad pero afirmar eventualmente el error o, en palabras cartesianas, más allá es el límite de lo incierto. (Descartes 1973, 58).

Descartes busca que la filosofía encuentre y ponga un fundamento que sea firmum, immobile, certum \& inconcussum (Descartes 1973, 24). Estos adjetivos serán el origen de la conocida frase "fundamentum inconcussum veritatis" acuñada por Heidegger para sintetizar la filosofía moderna y, según su interpretación, un modo históricamente dominante de la conceptualización del ser y la ciencia. La formulación tal y como la instauró Heidegger no es directamente lo que plantea Descartes. Los adjetivos que éste último usa se refieren al punto de apoyo que busca para, al modo que lo hizo Arquímedes, poder poner nuevamente en movimiento a la metafísica en tanto saber verdadero. Ese punto que busca lo describe ante todo como cierto (certum). Y si todas las Meditaciones metafísicas están transitadas por la necesidad de certeza, esto da cuenta de que la filosofía post Galileo se encontraba en profunda crisis de verdad. Sin entrar en detalle en la filosofía cartesiana, nos interesa aquí rescatar tres aspectos fundamentales de esta re-fundación de la metafísica que él pretende. Dichos aspectos nos guiarán a la filosofía kantiana y al tratamiento del concepto de límite por parte de Hegel.

En primer lugar, la crisis de la filosofía estaría dada, para Descartes, a partir de la metodología científica de la misma. Descartes rompe con la metafísica tradicional y comienza a desarrollar su propia metafísica a partir de 1630 (Alquié 1965, 46). Ello se ve acompañado por el desarrollo de un nuevo método universal para la ciencia, incluyendo la metafísica (Gueroult 1953, 17). La metafísica que llega hasta él se había basado, desde Aristóteles, en un método que constaba de dos aspectos centrales: los pasos metódicos que iban de la experiencia al entendimiento y el aseguramiento de la calidad científica de la metodología mediante el uso de la lógica silogística. Con el segundo elemento no habrá problemas al comienzo de la modernidad, es el medio de prueba formal que requiere la matemática $\mathrm{y}$, en especial, la geometría euclidiana, aunque se preferirá por supuesto el método del análisis matemático. Pues, aunque el método silogístico sería en general apropiado para deducir correctamente las consecuencias a partir de premisas dadas, sin embargo, no serviría para buscar dichas premisas cuando estas faltan (Cassirer 1922, 28). Por ello, el problema central es la construcción del conocimiento verdadero a partir de la experiencia. El problema es seguir aceptando la frase expresada en latín, que reza: Nihil est in intellectu, quod prius non fuerit in sensu. Dicha frase que según las investigaciones filológicas se remonta por lo menos hasta Beda el Venerable en el siglo VII, cruza la edad media con varios testimonios de la mano de, entre otros, San Buenaventura, Santo Tomás de Aquino y Duns Escoto, arriba al siglo XV con Pico della Mirandola y continúa su camino hacia Locke mediante Pierre Gassendi (Cranefield 1970, 79). Finalmente, la misma idea, si bien con otra formulación, quedará en la Crítica de la razón pura cuando Kant 
afirma con contundencia: "Sin sensibilidad no se nos daría ningún objeto y sin entendimiento ninguno podría ser pensado. Pensamientos sin contenido son vacíos, percepciones sin conceptos son ciegos" [A 51] (Kant 1990, 95). Kant resalta la palabra vacíos.

Esta interdependencia fundamental entre pensar y sensibilidad, que fundó la filosofía misma, es la que entra en crisis con Galileo, llega a la filosofía con Descartes, se desnuda con Kant y se -intentará- resolver con Hegel. Y en el núcleo de dicha interdependencia fundamental nos encontramos con el límite: el límite del pensar, de la realidad y del conocimiento. Porque lo que se oculta en la famosa frase es que el entendimiento está limitado por un lado por la sensibilidad y, por otro, por la necesidad lógica. Por supuesto hablamos de un entendimiento que pretende hacer filosofía científica. Conocimientos hay muchos y variados, desde Platón hasta nuestros días se tipifican y muestran sus ámbitos de validez, su eficacia comunicativa y sus estrategias manipuladoras. De la opinión a la charlatanería, de las fake news al pseudo-conocimiento obtenido al ver un par de videos on-line, sin olvidar las creencias irracionales y los dogmatismos ingenuos que llegan hasta las mas altas esferas académicas y científicas. Pero la filosofía que siempre supo identificar estos tipos de saberes y pseudo saberes, también supo ordenarse y encontrar los caminos metodológicamente seguros para el conocimiento verdadero de la realidad. No hace falta esclarecer que, por lo menos desde Hegel queda como algo fundado que todo conocimiento verdadero se desarrolla históricamente y tiene validez limitada y circunscrita a su tiempo. Y esto lo enseña la historia misma de la filosofía cuando nos muestra a un Descartes desesperado buscando hacer pie en algo firme para poder reconstruir la filosofía como ciencia verdadera de lo real: Refleja en su época el mostrarse de la caducidad de la metafísica clásica como conocimiento verdadero. Y esto lo lleva a indagar -via negationis- la justificación empírica del fundamento (ciencia) y los límites de esa experiencia (empeiria).

Quizá sea oportuno señalar aquí que la famosa frase citada más arriba no se encuentra formulada de ese modo en Aristóteles, aunque sí podemos encontrar algún texto que nos aclara el sentido y el alcance que debería tener la misma - por lo menos para Aristóteles. La interdependencia de conocimiento inteligible y experiencia sensible queda manifiesta en tanto, para Aristóteles, incluso las formas matemáticas están contenidas en las formas sensibles. Esto se puede ver claramente en el De Anima [432a] (Aristoteles 1995, 186) o en De Sensu [445b] (Aristoteles 1931,316) en donde, criticando a Platón y los pitagóricos se afirma que "el entendimiento no puede entender las cosas externas sino es por medio la sensibilidad". En la edición de Beare y Ross se traduce: "la razón no aprehende objetos en el espacio, excepto cuando éste actúa en conjunción con la percepción sensible". La referencia al espacio ayuda a conectar con Kant y permite decir, prima facie, que esta afirmación aristotélica podría ser suscrita sin problema con Kant, el que en la introducción a la Crítica de la razón pura critica aristotélicamente a Platón usando una metáfora absolutamente gráfica: La pequeña paloma que siente la oposición del aire al volar se representa que podría hacerlo mejor y sin dificultad en el vacío, pero en el vacío carece de aquello que se le antojaba un obstáculo y que en realidad es su sustento. Sin aire no hay vuelo, 
así como sin aisthesis no hay pensar, aunque ambos, aire y sensibilidad, incomoden [A5 / B8-9](Kant 1990, 43). Ahora bien, Kant no suscribiría el hecho de que los conocimientos matemáticos requerirían la misma experiencia que cualquier conocimiento. Y en ese sentido continuaría el camino de Descartes en el que la ciencia nueva no puede construirse a partir de conocimientos sensibles o de juicios a posteriori. Kant conoce a Descartes, tiene sus libros en su biblioteca (Ferrari 1971, 479), pero ante todo habría reconocido en Descartes la legitimidad metodológica del "yo pienso" como un "racionalismo problemático" conforme a un modo de pensar filosóficamente fundado (Gatto 2017, 146). Que la sensibilidad es necesaria para el conocimiento está claro para todos, pero hasta dónde, ésa es la pregunta. Descartes o Kant se enfrentan con que la determinación de los límites del conocer y del pensar se mostraría como la tarea requerida para hacer filosofía, tarea que debe ejercerse "semel in vita" para fundar toda posibilidad de una filosofía como ciencia de la verdad (Descartes 1973, 17). De este modo, establecer los límites del sentir y del pensar, pensar el límite de mi conocimiento, se constituiría como la tarea inicial del pensar.

Allende este aspecto metodológico y crítico de pensar los límites del saber, de la razón y del sentir, habría, según lo expuesto hasta aquí, un aspecto lógico esencial que cruza la historia de la filosofía como uno de sus leit motiv fundamentales: Pensar los límites requiere que el pensar se piense a sí mismo en sus límites. Y en este punto es donde quisiéramos introducir la exposición de Hegel respecto al límite. El lugar sistemático es sin duda en la primera parte de la Lógica del Ser que trata sobre la cualidad. En el segundo capítulo de esta parte, dedicado al ente o al ser determinado (Dasein), encontramos las palabras claves que estamos considerando aquí: Grenze, Schranke, Endlichkeit. Las dos primeras son palabras comunes a la Crítica de la razón pura kantiana. La traducción más inmediata es: Frontera (Grenze), límite (Schranke), finitud (Endlichkeit). Yo he traducido en este caso a las dos primeras palabras como: borde en lugar de frontera, barrera en lugar de límite. Borde se refiere a los contornos del ser y del pensar. No hace falta recurrir a la antropología social o al concepto de frontera geográfica para entender que frontera es borde. Desde el horizonte de una experiencia inmediata uno podría decir que en el borde uno se para y, haciendo pie allí, se puede balancear para ambos lados, para/hacia lo seguro que está a la espalda, para/hacia lo incierto que se abre con/como un abismo enfrente. Lo seguro sería lo recorrido, lo que se ha hecho propio en tanto ser apropiado. La propia existencia determinada y recorrida en mi tiempo vivido (y sólo en este sentido cabría traducir a "Dasein" por ser-ahí). Lo seguro sería lo que me pertenece por apropiación y a lo que pertenezco. Frontera como borde sería así la apertura al futuro y a un más allá de lo seguro. Kant se refiere a esta idea en los más de ciento ochenta usos que hace de Grenze en la Crítica de la razón pura. Grenze sería el borde, en todo caso, de transición entre lo seguro de la experiencia y lo que se abre más allá de ella. El más allá que es el lugar que Kant presenta como el terreno de las posibles contradicciones y oscuridades: el vacío en el que quiere volar la paloma de la razón, el campo de batalla que se llama metafísica. Grenze como borde implica también un intersticio: el borde tiene un espesor, que podría pensarse 
como un entre desde y dónde Kant mismo pensaría; es el espacio dinámico entre los paréntesis de la epojé donde ya Descartes puso a Dios, - y con ello a alma (res cogitans) y mundo (res extensa) (Descartes 1973, 22). Grenze como borde podría así ser considerado el espacio cualitativo desde y dónde se piensa el pensar crítico, el pensar fundante de la nueva filosofía, el principio supremo del idealismo transcendental.

Schranke, pensado como barrera, quiere decir según nuestra interpretación la indicación forzosa que detiene la marcha, el impedimento que frena. Si Grenze en tanto borde nos pone en la ambivalencia, (en el espacio de juntura de lo seguro y lo a descubrir, de la experiencia y los vuelos de la razón, del pasado y del futuro); Schranke, como barrera puede verse como los controles fronterizos que impiden el paso a los que no estén en regla. Schranke sería la barrera de control que le debe impedir al entendimiento salir del país de la experiencia posible. Y la Crítica de la razón pura consiste en ponerle a la razón barreras de control "fijas y seguras" [B 22] (Kant 1990, 53) (No por algo se hablará de una disciplina de la razón pura en un uso dogmático - (Kant 1990, 654 ss.). Ella - la Crítica de la razón pura - delimita los territorios de la sensibilidad, del entendimiento y de la razón misma y establece los requisitos para pasar de uno a otro, así como las reglas para habitarlos. Pero justamente la infraestructura montada por Kant es la que entra en crisis por su rigidez asimétrica con la realidad. Acomodar la estructura del conocimiento verdadero de la realidad, refaccionarla o cambiarla ser incluso visto como la tarea de la filosofía clásica alemana hasta Hegel (Cassirer 1922, 5). Y justamente es este último el que va a intentar poner al mapamundi de la filosofía transcendental en coordinación con la experiencia y replantear, desde allí, el problema de los límites de la razón.

\section{Hegel}

Que la experiencia sensible pueda ser fuente del conocimiento científico y, por lo tanto, verdadero, es algo que como hemos presentado trasvasó problemáticamente toda la filosofía desde Descartes hasta Kant, y fue uno de los elementos que - por ejemplo bajo la forma de la disputa realismo vs. idealismo - ayudó a delinear los sistemas filosóficos de la época entre este último y Hegel (Jaeschke y Arndt 2012, 26-30). Incluso la liberación de los límites impuestos por el modelo de racionalidad kantiano fue un interés común de Fichte, Schelling y Hegel. Como dice Werner Marx:

Creo que el filosofar contemporáneo debería recordar siempre esto: Fichte, Hegel y el joven Schelling [...] estaban convencidos de [...que] en la conciencia finita hay -como una creación de la nada- una dimensión originaria, autoproductora, que no está limitada por los objetos [... Esto] fue considerado por ellos como el principio sobre cuya base se quería cumplir la expectativa de Kant de »la filosofía como ciencia«. (Itálicas mías. Marx 1977, 67-89) 
El tema es encarado en la Introducción de la Fenomenología del espíritu (en adelante: Fenomenología) de un modo irónico y hasta despectivo respecto a Kant y a Schelling. Hegel podría haber sido más profesional, es decir, como nuestra época entiende la objetividad aséptica de los comentarios académicos. Pero eligió, y se podría decir que lo mantuvo toda su vida, un tomo más combativo respecto a determinados aspectos de los sistemas filosóficos que lo precedieron. Y seguramente este tipo de apropiación bélica de la historia de la filosofía no estaría lejos de las exigencias epistemológicas de la propia filosofía de Hegel: una filosofía fundada en la contradicción hasta sus últimas consecuencias. En este tono entonces critica a los que ponen a la experiencia fuera de la posibilidad de construcción metodológica del conocimiento verdadero de la realidad, esto es, la ciencia. Y esta crítica la defiende a pesar de las incluso diferencias sustanciales en sus proyectos filosóficos. (Sedgwick 2008, 108-109). Y lo hace de un modo tan contundente y decidido que incluso el primer título de la Fenomenología es Ciencia de la experiencia de la conciencia (Hegel 1980, 469-471). Sólo en el transcurso de la producción de esta obra se le manifestaría a Hegel un nuevo concepto que pueda decir la experiencia de la conciencia: un concepto que contenga lo inherente a toda experiencia -el tiempo- y que contenga a todos los objetos del saber -no sólo a los no-humanos- y a todos los cognoscentes. Un concepto que exprese todas las capacidades inteligibles de los sujetos individuales y de los seres objetuales que se le presentan (aunque mediados por la subjetividad), e incluso todo ello en un carácter epistémico intersubjetivo (Jaeschke 2003, 190; Valls Plana 1994, 377-8). Este concepto sería el concepto de espíritu, y por ello el título definitivo de la obra debía llegar a ser el fiel reflejo de ello: la manifestación del concepto de espíritu, la fenomenología del espiritu, la manifestación de la totalidad de la experiencia sistemáticamente presentada (Heidegger 1988, 37).

¿Cómo puede haber una ciencia a partir de la experiencia? Esta pregunta que estructura el inicio de las Meditaciones metafísicas cartesianas da comienzo asimismo a la Fenomenología. Descartes y Kant -y sus descendencias filosóficas por amor o por odio- situaron uno de los ejes de la discusión filosófica en los límites a los que llega la capacidad de la experiencia sensible de brindar conocimiento cualitativamente asegurado para poder hacer uso de él en la construcción de una teoría científica. Incluso se ha llegado a ver la unidad de dichos períodos filosóficos bajo la característica común de un proyecto para la aprehensión del "mundo de la experiencia en procesos de conciencia" (Windelband) o como, según Rosenkrankz, una empresa de superación de la flosofía kantiana de la "cosa en sí" (Jaeschke 2020, 403-4). Que "los sentidos fallan" (Descartes 1973, 18) abre en la historia de la filosofía un apasionado debate acerca de la percepción y del conocimiento que esta produce. Desde las objeciones a las Meditaciones mismas, pasando por el empirismo inglés, la filosofía pasa de un escepticismo completo respecto a la percepción a -ya en Kant- la convicción de que la experiencia sensible es el origen del conocimiento, y esto sin lugar a duda. Como ya lo referimos más arriba, esto puede ser suscrito sin contradicción tanto por Aristóteles como por Kant. Solo que la experiencia habría quedado 
recortada a los juicios sintéticos a priori que puede emitir la razón kantiana respecto a las percepciones sensibles, esto es, a que toda percepción sucede en las estructuras apriorísticas de espacio y tiempo como matriz fundamental e inicial de toda experiencia posibles de objetos: de objetos con extensión se entiende, porque de objetos no pasibles de una percepción sensible no puede haber propiamente conocimiento. Esta circunscripción del conocimiento se expresa, como hemos visto, de la mano de las palabras Grenze y Schranke entendidas como borde y barrera. Y es justamente aquí donde podemos decir que interviene Hegel para destrabar la posibilidad de que haya conocimiento de todos los objetos del pensar. Y esto no se trata naturalmente de querer extender el conocimiento filosófico/científico más allá de toda experiencia posible. No es el objetivo de Hegel, ni puede serlo, hacer una filosofía de los fantasmas de la razón. Se trata mas bien de que la superación del carácter estático de los conceptos de borde y barrera sería necesaria para superar las presuntas deficiencias del sistema kantiano mismo respecto a la posibilidad de un conocimiento integral, racional y filosófico de los fenómenos o objetos. Si el miedo consiste en que yendo más allá de aquellos bordes y barreras se perdería la posibilidad de tal conocimiento, Hegel intentará demostrar que dicho miedo es en realidad el verdadero problema para alcanzar aquel conocimiento verdadero.

Borde o frontera, en tanto límites de la razón, serían mas bien los culpables de no alcanzar aquello que justamente quieren asegurar (Hegel 1980, 54). La solución que nos presenta Hegel es doble: a) por un lado se muestra bajo el ropaje de las experiencias que la conciencia natural adquiere de los diversos modos de racionalidad que se configuran paulatinamente acorde a los diversos mundos de objetos que se le van presentando. Incluso los nombres de la capacidad intelectiva humana irán cambiando a lo lapso de la Fenomenología desde la conciencia inicial hasta el espíritu absoluto final, pasando por entendimiento, autoconciencia y razón; b) por otro lado se presenta la superación de borde y frontera desde la Ciencia de la Lógica.

a) La metamorfosis de la capacidad humana cognoscente baila al compás de las metamorfosis de los objetos que se le presentan (Hegel 1980, 60). Se podría objetar que este camino de transformaciones en pareja entre la conciencia-razón y sus objetos es un camino arbitrario, el camino que Hegel decide presentarnos, del mismo modo que el camino de salida de la caverna es el que elige presentarnos Platón en su República [514a-517a] (Plato 2001, 555-563). Y es verdad que dicho camino, tal como se presenta en la Fenomenología está circunscrito en una historia idealista de la autoconciencia (Düsing 1993), circunscripción por otro lado histórica y que forma parte de la destinación, del hado de cada pensador y del desafío de la filosofía post-kantiana de superar las limitaciones de la finitud (Heidegger 1997, 279), que como hemos señalado más arriba ella conllevaba. Pero más allá de estas limitaciones inherentes a la naturaleza humana fáctica del filósofo y de su época, el camino de la Fenomenología nos presenta una historia que se construye con dos actores que se metamorfosean constantemente y así tejen la historia de la ciencia (fenomenológica) que corre en paralelo a la historia del mundo y de sus objetos. La pala- 
Los límites del pensar: Hegel en diálogo con Kant

Victor E. Duplancic

bra que dice la dinámica de ese intercambio in crescendo es experiencia. Ese intercambio es un "movimiento que la conciencia ejerce en su saber como en su objeto" y a partir del cual "surge para ella el nuevo objeto verdadero" (Hegel 1980, 60). Pero esos actores (el saber de la conciencia cognoscente y el objeto), si bien son necesarios, no son iguales ni alcanzan por sí solos a constituir la experiencia. Primero, porque hay una asimetría a favor de la conciencia que conoce (Hegel 1980, 61; Beuthan 2008, 83). Segundo, porque la experiencia propiamente, para que pueda constituir un "sistema de la ciencia", no se reduce a lo que le pasa a la conciencia con sus objetos, puesto que esta misma no puede "ver" el proceso de constitución de saberes verdaderos, ella siempre se atiene a una verdad pasajera y unilateral. Solo el nosotros (que devendrá finalmente espíritu absoluto), es el que puede tener experiencia. Y en ello se transciende la individualidad del sujeto cognoscente para incluirlo en la historia científica de la humanidad, de la especie, del género humano. Presentar que la solución de la razón cogitante solipsista es la comunidad científica y humana en su desarrollo histórico es justamente el aporte original y filosóficamente transcendental que hace Hegel.

b) La tematización de Grenze = borde y Schranke = barrera en la sección de la Lógica destinada a la cualidad indican que para Hegel está claro que ni las barreras ni los bordes fronterizos de la experiencia, el entendimiento y la razón tienen que ver con el espacio o la naturaleza. Son espacios-tiempos cualitativos. Que, en el caso de demostrarse siendo filosóficamente científicos, coincidirían con el sistema temporal-espacial de la naturaleza. Es decir, si el sistema filosófico de Hegel es verdadero, entonces podrá decir, enunciar lo que es, la realidad, en la forma racional lingüística de un discurso filosófico. Del mismo modo para Kant las fronteras o bordes de la razón serían equivalentes a las de la naturaleza [B 753](Kant 1990, 667).

Hegel trata estos temas en la Lógica del ser. En la primera parte de la misma, en la sección "Determinación (Cualidad)", luego de llegar a un ser determinado (Dasein) que tiene en sí la movilidad propia de la negatividad dialéctica que lo hace salir de la dualidad ser/nada, nos encontramos con la finitud de ese ser determinado. Que ese ser determinado no se constituye por sí sólo como el yo cartesiano queda claro a partir de la dialéctica de determinación cualitativa que sucede en la dinámica algo/otro. Esta dinámica deviene en un ser determinado (ente) simple, el cual tiene su ser-en-sí a partir del retorno mediado por el ser-para-otro (Hegel 1985, 110).

Como al final de la dialéctica de la autoconciencia de la Fenomenología, nos encontramos con una figura que se levanta a partir de la dialéctica de la diferencia y de la identificación entre dos seres determinados. La categoría cualitativa que Hegel piensa acá es la de la determinación esencial destinada (Bestimmung) de algo, por ejemplo, el ser racional del ser humano:

La determinación esencial es la cualidad afirmativa como el ser-en-sí, para el cual el algo siendo en su relación frente a otro, por el cual sería determinado, permanece

Revista de Humanidades de Valparaíso, 2021, No 17, 193-208

(c) $(1)(9)$ CC BY-NC-ND 
relacionado, y se mantiene en su igualdad consigo mismo, y la hace valer en su serpara-otro... La determinación esencial del hombre consiste en la razón que piensa [...] (Hegel 1985, 110-111)

Como vemos Hegel incorporaría a algo similar a al atributo de Spinoza la movilidad de la negación determinada ya puesta en uso filosófico desde la Fenomenología. Y esto dice mucho: las categorías (las determinaciones esenciales de las cosas) no pueden ser postuladas ni derivadas de los juicios, deben ser deducidas a partir de su propia dinámica de constitución racional (Hegel 1980, 135). Y en ello justamente nos encontramos con el dilema del límite o borde (Grenze) del ser determinado (ente). En la deducción de las determinaciones del ser (esencia y accidente del ente) Hegel ha introducido la necesidad de la determinación a partir de la relación de dos actores que van cambiando en quienes lo interpretan, pero como figuras de la obra son siempre los mismos: el en-si, el para-otro. Ello implicaría dos cosas: a) que ambos actores se diferencien esencialmente en sus roles, sean determinados, tengan límites y fronteras claras e inmutables, b) que sin embargo puedan relacionarse, cambiar de lugar, interactuar. Esto mismo aplicado al tema que nos ocupa significa: los límites de la razón deben asegurar su calidad epistemológica pero no puede ello implicar renunciar a la posibilidad de pensar sólo bajo las condiciones de un pensar a priori como el modo racional de las matemáticas o la geometría (Kant), esto es, sin relación con lo allende-barrera, con lo extra-borde.

Pensar el borde (Grenze) como espacio cualitativo de interrelación sería la clave para poder extender legítimamente el uso de la razón kantiana a terrenos no permitidos, se constituiría en algo así como el documento para salir al exterior con pasaporte válido, con identidad oficial que implique un estatus de reconocimiento jurídico y ético suficiente por parte de los otros, de los extranjeros. Hegel es aquel que entendió y escribió que lo propio sólo se constituye realmente a partir de su relación esencial con lo ajeno. Y que ello implica una constante dinámica de alienación (Entäußerung), enajenación (Entfremdung) y retorno a sí (an-und-für-sich-sein, Insichgehen).

Schranke (barrera) no es ya entonces el control fronterizo que impide que el pensar se aventure en terrenos no seguros para un apriorismo matemático, es autodeterminación esencial de la cosa, sí, de la cosa mediada por el pensar, en este caso por la filosofía de Hegel operante en su Lógica. Y con ello nos indica el propio Hegel que existe otra posibilidad filosófica de concebir las barreras del pensar: "El borde propio (Grenze) de algo (Etwas), así puesto por él como algo negativo que es al mismo tiempo esencial, no es sólo un límite como tal, sino una barrera (Schranke)". (Hegel 1985, 118) O como dice Sözer: "la barrera es el borde puesto y negado [...]" $(2009,180)$

Pero pensar la barrera como el lugar donde no se puede pasar es, para Hegel (irónicamente) contradictorio:

Revista de Humanidades de Valparaíso, 2021, No 17, 193-208

(c) $(1)(9)$ CC BY-NC-ND 
[...] pues una determinación cualitativa, borde, es en cuanto barrera sólo determinada en contraposición con su otro por antonomasia, es decir, en relación a su ilimitación (Unbeschränktes); lo otro de una barrera es justamente el pasar por arriba de ella. (Hegel 1985, 121)

Si se pudiera determinar una barrera limitante, así como piensa Kant, ya la habríamos superado al pensarla o imaginarla. De este modo sería una pura arbitrariedad afirmar:

[...] que no existen conceptos de totalidad suficientemente precisos para navegar por el ámbito especulativo de las grandes geografías lógicas. Mas bien se trata de lo contrario, cuando se advierte que la renuncia a estos conceptos es ya en sí misma un signo de habla imprecisa e irreflexiva. (Stekeler-Weithofer 2020, 475)

Con esto Hegel entendería también que cualquier cosa es una cosa en una red de relaciones cualitativas. Comprender que esas relaciones nos involucran sería lo que nos permite el acceso al conocimiento del objeto. La comprensión de dichas relaciones no sería otra cosa que la determinación del objeto. Y esta determinación tendría, para Hegel, por lo menos un doble sentido: a) Por un lado está la determinación como está en la cosa, b) por otra la determinación que ponemos en el acto de conocer o el cómo es la cosa determinado en relación a otro. A su vez, ser determinado también implicaría c) la movilidad hacia el futuro de la cosa, su posible llegar a ser, su destino, su enérgeia monádica (Bestimmung); y también d) el elemento más superficial de la determinación del ente: su mostrarse siendo así o asá, su modo de aparecer siendo no esencial que Hegel denomina Beschaffentheit, complexión, que, como se refirió, es lo mas parecido a accidente o modo. En este contexto de la determinación del concepto cualitativo de determinación mismo Hegel concibe el borde, la frontera, esto es "die Grenze" como el no-espacio que dibuja y define los contornos de un algo respecto a un otro. Y es justamente un no espacio porque estamos en el terreno de la cualidad, de la determinación cualitativa de algo. Este delineamiento de los bordes de un algo (la determinación esencial de una cosa) se produciría, a diferencia de Kant, retomando de algún modo el motor de la duda escéptica cartesiana. Claro que Hegel habría tomado aquí el modelo del Parménides de Platón (Hegel 1980, 48) y lo llama escepticismo que se consume a sí mismo (Hegel 1980, 56), estos es, la dialéctica (Hegel 1980, 45). La dialéctica como método de la filosofía especulativa le permitiría a esta llegar a ser ciencia, devenir lo que ella siempre fue y estuvo puesto en duda desde Descartes hasta Hegel.

\section{Conclusión}

Hegel piensa el borde o la frontera como la articulación moviente, como la determinación dialéctica de los contornos de algo con su otro. Esto se refiere a un algo y a un otro determinados cualitativamente como ente, pero también se aplicaría a un algo y un 
otro absolutos, esto es, al ser y a la nada, o al yo que pone y al que padece, o al yo y el mundo, al sujeto y a la naturaleza, al yo transcendental y a sus objetos metafísicos. No se trata sólo de superar la finitud del ente, sino de la posibilidad de superar todas las finitudes (Hegel 1985, 181). El borde, la frontera, constituirían un lugar de paso, el lugar-momento dinámico del estar-llegando-a ser lo propio y lo ajeno, el pensar y el ser, el sujeto y la naturaleza, un "punto de intersección" (Sözer 2009, 178). Y como dicho lugar-momento cualitativo se constituiría en la inter-relación moviente entre razón y cosa -o de la subjetividad y la objetividad como formas de la finitud (Hegel 1985, 181), y esta interrelación que determina en ambas direcciones según lo expuesto sería la experiencia, ello permitiría la experiencia científica (en tanto dialéctica) del ser. Con ello Hegel llevaría al borde kantiano a ser un lugar de tránsito y apertura, lugar que se mueve acorde al movimiento de la razón pero también de sus objetos. Pero, ciertamente, Hegel no habría llegado a ello sin Kant. Kant sigue vivo en la filosofía de Hegel.

Hegel critica a Kant de que deja encerrada a la razón dentro de los límites de la finitud, pero en el apartado sobre "Finitud" de su Ciencia de la Lógica, estaría presentando el movimiento lógico para justificar que la razón piense totalidades, aunque no justifica por supuesto con ello la extra-limitación arbitraria del campo experiencial que tanto le importa a Kant (Hegel 1985, 122). Sólo se recorre su posibilidad lógica. La realización de dicha tarea se hará como hemos visto antes, por un lado a través del concepto de experiencia fenomenológico, $\mathrm{y}$, desde el punto de vista absolutamente lógico, por el otro lado, la realización de la tarea de superar las dicotomías sujeto-objeto, substancia-sujeto, mediante la negación de la negación operante en la finitud, -tarea de toda la Lógica-, ya que transvasaría la doctrina del ser, pasando por la doctrina de la esencia y llegando incluso hasta la del concepto (Sözer 2009, 184). Dicha experiencia no se acaba naturalmente con la Fenomenología o en la Lógica, se continúa en el desarrollo de la obra de Hegel. La posibilidad epistemológica está dada por la dialéctica como metodología de doble negación que con su ritmo envolvente permite pensar distintos campos o mundos racionales, adaptando, en cada caso, la racionalidad conceptual requerida por su objeto de estudio.

Hegel descubre la posibilidad de la ciencia pensando sus bordes, sus entre/s, cruzando las contradicciones filosóficas que se le presentan epocalmente. Y este entre que opera como un tercero en la relación de dos contradictorios, es el lugar originario, arquetípico y fundamento absoluto de la relación entre ambos (Sözer 2009, 175). Borde sería así no un límite controlado por barreras, sino el lugar fundante de la relación y, por lo tanto, de la estructura del sistema, puesto que esa relación dialéctica no es otra cosa que experiencia, y esta, en cuanto método, es "el todo expuesto en su pura esencialidad". (Hegel 1980, 35) 
Los límites del pensar: Hegel en diálogo con Kant
Victor E. Duplancic

\section{Referencias bibliográficas}

Alquié, F. (1965). Science et Metaphysique chez Descartes. Paris: Centre de Documentation Universitaire.

Aristoteles (1931). Parva Naturalia. En G. R. T. Ross y J. I. Beare (eds.), Meteorologica, De Mundo, De Anima, Parva Naturalia, De Spiritu. Oxford: Clarendon Press.

Aristoteles. (1995). Über die Seele. Griechisch-Deutsch. Hamburg: Felix Meiner

Beuthan, R. (2008). Hegels phänomenologischer Erfahrungsbegriff. En K. Vieweg y W. Welsch (eds.), Hegels Phänomenologie des Geistes. Ein kooperativer Kommentar zu einem Schlüsselwerk der Moderne, pp. 79-94. Frankfurt am Main: Suhrkamp.

Cassirer, E. (1922). Das Erkenntnisproblem in der Philosophie und Wissenschaft der neueren Zeit. Berlin: Bruno Cassirer

Cranefield, P.F. (1970). On the Origin of the Phrase NIHIL EST IN INTELLECTU QUOD NON PRIUS FUERIT IN SENSU. Journal of the History of Medicine and Allied Sciences, XXV(1), 77-80. https://dx.doi.org/10.1093/jhmas/XXV.1.77

Descartes, R. (1973). Meditationes de Prima Philosophia. Paris: Vrin

Düsing, K. (1993). Hegels "Phänomenologie" und die idealistische Geschichte des Selbstbewußtsein. Hegel-Studien, 28, 103-126. https://www.jstor.org/stable/26598228

Ferrari, J. (1971). La bibliothèque de Kant et les sources françaises de sa philosophie. Les Études Philosophiques, 4, 477-482. http://www.jstor.org/stable/20846102

Gatto, A. (2017). La maschera cartesiana: René Descartes nella Critica della ragion pura di Kant. Con-textos Kantianos. International Journal of Philosophy, 1(5), 138-149. https://dx.doi. org/10.5281/zenodo. 805927

Gueroult, M. (1953). Descartes selon l'ordre des raisons (I). Paris: Editions Montaigne

Hegel, G.W.F. [GW 11] (1978). Wissenschaft der Logik Bd. 1. Die objektive Logik (1812/1813). En F. Hogemann y W. Jaeschke (eds.). Gesammelte Werke, Vol. 11. Hamburg: Meiner.

Hegel, G.W.F. (1980). Phänomenologie des Geistes. Hamburg: Meiner

Hegel, G.W.F. (1985). Die Lehre vom Sein (1832). Hamburg: Meiner

Heidegger, M. (1988). Hegels Phänomenologie des Geistes. Wintersemester 1930-31. Frankfurt am Main: Klostermann.

Heidegger, M. (1997). Der deutsche Idealismus (Fichte, Schelling, Hegel) und die philosophische Problemlage der Gegenwart. Frankfurt am Main: Klostermann.

Heidegger, M. (2006). Identität und Differenz. Frankfurt am Main: Vittorio Klostermann.

Jaeschke, W. (2003). Hegel-Handbuch. Leben - Werk - Schule. Stuttgart: J.B. Metzler.

Jaeschke, W. (2020). Zur Genealogie des Deutschen Idealismus. Konstitutionsgeschichtliche Bemerkungen in methodologischer Absicht. En Hegels Philosophie, pp. 393-415. Hamburg: Meiner. 


$$
\begin{gathered}
\text { Los límites del pensar: Hegel en diálogo con Kant } \\
\text { Victor E. Duplancic }
\end{gathered}
$$

Jaeschke, W., Arndt, A. (2012). Die klassische Deutsche Philosophie nach Kant Systeme der reinen Vernunft und ihre Kritik 1785 - 1845. München: Beck.

Kant, I. (1990). Kritik der reinen Vernunft. Hamburg: Meiner

Marx, W. (1977). Aufgabe und Methode der Philosophie in Schellings System des transzendentalen Idealismus und in Hegels Phänomenologie des Geistes. En Schelling: Geschichte, System, Freiheit, pp. 63-99. Freiburg, München: Alber.

Plato. (2001). Politeia (Der Staat). Darmstadt: WBG.

Secada, J. (2002). Introducción. En Marital Gueroult (ED.), Descartes según el orden de las razones, pp. I-XLIII. Caracas, Venezuela: Monte Ávila.

Sedgwick, S. (2008). Erkennen als ein Mittel. Hegels Kant-Kritik in der Einleitung zur Phänomenologie. En Vieweg, K. Welsch, W. (eds.), Hegels Phänomenologie des Geistes. Ein kooperativer Kommentar zu einem Schlüsselwerk der Moderne, pp. 95-111. Frankfurt am Main: Suhrkamp.

Sözer, Ö. (2009). Grenze und Schranke - das Mal des Endlichen. En A. Arndt y C. Iber (eds.), Hegels Seinslogik, pp. 173-185. Berlin: Akademie.

Stekeler-Weithofer, P. (2020). Die objektive Logik. Die Lehre vom Sein. Qualitative Kontraste, Mengen und Maße. Hamburg: Felix Meiner.

Valls Plana, R. (1994). Del Yo al Nosotros. Lectura de la Fenomenología del Espíritu. Barcelona: PPU. 